\title{
WHEAT GRAIN QUALITY FORECASTING BY CANOPY REFLECTED SPECTRUM
}

\author{
Wenjiang Huang*, Jihua Wang, Xiaoyu Song, Chunjiang Zhao, Liangyun \\ Liu \\ National Engineering Research Center for Information Technology in Agriculture, P.O. Box \\ 2449-26, Beijing, 100097, China \\ * Corresponding author, Address: P.O. Box 2449-26, Beijing, 100097, P. R. China, Tel: +86- \\ 10-51503676, Fax: +86-10-51503750, Email: yellowstar0618@163.com
}

\begin{abstract}
Advanced site-specific determination of grain protein content by remote sensing can provide opportunities to optimize the strategies for purchasing and pricing grain, and to maximize the grain output by adjusting field inputs. Field experiments were performed to study the relationship between grain quality indicators and foliar nitrogen concentration. Foliar nitrogen concentration at the anthesis stage is suggested to be significantly correlated with grain protein content, while spectral vegetation index is significantly correlated to foliar nitrogen concentration around the anthesis stage. Based on the relationships among nitrogen reflectance index (NRI), foliar nitrogen concentration, and grain protein content, a statistical evaluation model of grain protein content was developed. NRI proved to be able to evaluate foliar nitrogen concentration with a coefficient of determination of $R^{2}=0.7302$ in year 2002. The relationship between measured and remote sensing derived foliar nitrogen concentration had a coefficient of determination of $R^{2}=0.7279$ in year 2003 . The results mentioned above indicate that the inversion of foliar nitrogen concentration and the evaluation of grain protein content by NRI are surprisingly good.
\end{abstract}

Keywords: Winter wheat (Triticum aestivum L), Canopy reflected spectrum, Grain protein

Huang, W., Wang, J., Song, X., Zhao, C. and Liu, L., 2008, in IFIP International Federation for Information Processing, Volume 259; Computer and Computing Technologies in Agriculture, Vol. 2; Daoliang Li; (Boston: Springer), pp. 1299-1301. 


\section{INTRODUCTION}

Wheat (Triticum aestivum L) is one of the main grain crops in Northern China. It is important to evaluate wheat grain quality before the harvest. However, evaluating grain quality before it is ripe is difficult using current methods. Remote sensing can potentially rapidly determine the grain quality condition of crops over large areas. The objective of this paper was to determine a credible and applicable method to evaluate winter wheat foliar nitrogen concentration and grain protein content by in situ canopy reflected spectrum.

\section{MATERIALS AND METHODS}

The experiment was conducted at Beijing Xiaotangshan Precision Agriculture Experimental Base, in Changping district, Beijing $\left(40^{\circ} 10.6^{\prime} \mathrm{N}\right.$, $\left.116^{\circ} 26.3^{\prime} \mathrm{E}\right)$ from 2001-2002 and 2002-2003.

\section{RESULTS}

Grain protein indicators such as grain hardness, protein content, wet gluten content and dry gluten content. Grain starch indicators such as flour peak viscosity, trough, breakdown, final viscosity, and peak time. The correlation coefficients among grain hardness, flour final viscosity, and flour peak time were significantly positive, with correlation coefficients of 0.396 and 0.498 . Correlation coefficients between grain sedimentation value and flour final viscosity, flour peak time and flour trough were highly significantly negative, which were respectively $-0.616,-0.652$, and -0.399 . They did not reach robust correlations at $5 \%$ significance level among protein content, dry gluten content (grain protein indicators), flour trough, flour breakdown, flour final viscosity, and flour peak time.

Grain bread quality indicators include developing time, stability, elasticity, volume, and total score. The correlation coefficients among wet gluten, dry gluten content, sedimentation value (grain protein quality indicators), bread elasticity, and volume (grain bread quality indicators) were significantly negative. The correlation coefficients among wet gluten, dry gluten content, sedimentation value, total score, and specific volume were significant positive. They did not reach robust correlations at 5\% relativity level between protein content, bread elasticity, volume, total score, and specific volume.

The foliar nitrogen concentration at the anthesis stage was thus highly correlated to grain protein content. If the foliar nitrogen concentration at the anthesis stage could be monitored by remote sensing technology, the grain protein content could be evaluated. Foliar nitrogen concentration at anthesis stage is suggested to be significantly correlated with grain protein content, while 
spectral vegetation index is significantly correlated to foliar nitrogen concentration around anthesis stage. Based on the relationships among nitrogen reflectance index (NRI), foliar nitrogen concentration, and grain protein content, a statistical evaluation model of grain protein content was developed. Our results reveal good agreement between the measured foliar nitrogen concentration and NRI, with a coefficient of determination of $R^{2}=0.7302(n=240)$, which was very significantly positive $(\mathrm{r}(0.01,240)=0.181)$. The model of the relationship between foliar nitrogen concentration and NRI was validated using data from 2003. The coefficient of determination between remote sensing derived and the measured foliar nitrogen concentration from 2003 is 0.7279 , which is extremely significant.

This study showed robust correlations between NRI and foliar nitrogen concentration, suggesting that NRI is a promising indictor to predict winter wheat grain protein for winter wheat. The NRI proved to be able to evaluate foliar nitrogen concentration with a coefficient of determination of $\mathrm{R}^{2}=0.7302$ using the data from 2002. The relationship between foliar nitrogen concentration that was measured and derived by remote sensing had a coefficient of determination of $\mathrm{R}^{2}=0.7279$ in 2003 . The correlation between the grain protein content that was measured and that was derived from in situ canopy-reflected spectrum was $R^{2}=0.7661$ in 2003.

Our study contributes towards developing optimal procedures for predicting wheat grain quality through the analysis of canopy-reflectance spectrum data before the harvest of large areas. Using the results of this paper, we are developing some simple instruments with selected bands of sensitivity. For example, we are developing optical camera lens and sensors that focus on $570 \mathrm{~nm}$ and $670 \mathrm{~nm}$, which could be placed on agricultural machines traveling in the field. This would allow for on-site and non-sampling modes of crop growth monitoring, fertilizing, and water guidance without a priori knowledge. Such portable instruments can also estimate grain quality at the anthesis stage by the regression models of this paper.

According to the results of this paper, the relationships among NRI, leaf nitrogen concentration, and grain protein content were significant. A model for evaluating grain protein was established based on the transfer principle of foliar nitrogen concentration, which made it possible to optimize crop nitrogen management for grain quality.

Our results indicate that evaluating grain quality indicators using NRI spectral index is surprisingly good.

\section{ACKNOWLEDGEMENTS}

This work was subsidized by the National High Tech R\&D Program of China (2007AA10Z201, 2006AA10Z203), it was also supported by the State Key Laboratory of Remote Sensing Science (KQ060006), the program from Ministry of Agriculture (2006-G63). The authors are grateful to Mrs. Zhihong Ma, Mr. Weiguo Li and Mrs. Hong Chang for data collection. 